\title{
PENDUGAAN ANGKA PENGANGGURAN DI KABUPATEN PADANG PARIAMAN MENGGUNAKAN SMALL AREA ESTIMATION DENGAN PENDEKATAN HIERARCHICAL BAYES (HB) LOGNORMAL
}

\author{
MIA MAULIANI, MAIYASTRI, RITA DIANA \\ Program Studi S1 Matematika, \\ Fakultas Matematika dan Ilmu Pengetahuan Alam, Universitas Andalas, \\ Kampus Unand Limau Manis, Padang, Indonesia \\ email:miamauliani@ymail.com
}

\begin{abstract}
Abstrak. Informasi mengenai Tingkat Pengangguran Terbuka (TPT) yang tersedia sampai saat ini hanya bisa diketahui sampai pada tingkat kabupaten. Padahal untuk berbagai tujuan dan kepentingan maka informasi yang memadai yang bisa menjangkau area yang lebih kecil menjadi sangat penting. Penelitian ini bertujuan untuk medapatkan TPT pada level kecamatan menggunakan metode SAE dengan pendekatan Hierarchical Bayes (HB) lognormal. Hasil estimasi TPT dengan penduga HB menghasilkan nilai standar error yang lebih kecil daripada penduga langsung, sehingga penduga HB lebih baik dibandingkan penduga langsung.

Kata Kunci: Tingkat Pengangguran Terbuka, Hierarchical Bayes, Lognormal, Small Area Estimation

$\begin{array}{lll}\text { Diterima } & : & \text { 29 November } 2018 \\ \text { Direvisi } & : & 3 \text { Desember } 2018 \\ \text { Dipublikasikan } & : & 30 \text { Desember } 2018\end{array}$
\end{abstract}

\section{Pendahuluan}

Permasalahan pengangguran menjadi permasalahan serius yang terjadi di hampir seluruh wilayah termasuk di Kabupaten Padang Pariaman. Masalah pengangguran tidak hanya terkait dengan masalah ekonomi, tetapi berkaitan erat dengan masalahmasalah sosial. Informasi mengenai Tingkat Pengangguran Terbuka (TPT) yang tersedia sampai saat ini hanya bisa diketahui sampai pada tingkat kabupaten. Padahal untuk berbagai tujuan dan kepentingan maka informasi yang memadai yang bisa menjangkau area yang lebih kecil menjadi sangat penting. Untuk itu, diperlukan metode estimasi yang dapat memberikan tingkat akurasi yang lebih baik yaitu dengan mengkombinasikan antara data survei dengan data pendukung lainnya. Salah satu metode yang sering digunakan adalah Small Area Estimation (SAE). Small Area Estimation (SAE) adalah sebuah metode untuk memenuhi permintaan akan statistik pada small area yang akurat ketika hanya tersedia sampel yang sangat kecil untuk area tersebut atau bahkan untuk daerah yang tidak terambil sebagai sampel [1].

Terdapat beberapa metode yang digunakan dalam SAE, salah satunya dengan pendekatan hierarchical bayes (HB). Model HB memiliki keuntungan yaitu dapat 
mengatasi permasalahan pemodelan hirarki untuk jumlah data yang sedikit dan tidak seimbang baik pada tingkat bawah maupun pada tingkat yang lebih tinggi [2]. Berdasarkan hasil uji kesesuaian distribusi terhadap data tingkat pengangguran Kabupaten Padang Pariaman menggunakan uji Kolmogorov Smirnov, diperoleh nilai statistik Kolmogorov Smirnov untuk distribusi lognormal adalah 0,12017 dan $p$ value adalah 0,94222. Karena $p$-value lebih besar dari 0,05 maka dapat disimpulkan bahwa tingkat pengangguran di Kabupaten Padang Pariaman mengikuti distribusi lognormal. Oleh karena itu, tingkat pengangguran level kecamatan di Kabupaten Padang Pariaman dapat diduga dengan pendekatan Hierarchical Bayesian Lognormal.

\section{Kajian Pustaka}

\subsection{Distribusi Lognormal}

Distribusi Lognormal (LN) adalah distribusi kontinu positif, dengan fungsi kepadatan peluang:

$$
f\left(y \mid \mu, \sigma^{2}\right)=\frac{1}{y \sigma \sqrt{2 \pi}} \exp \left(-\frac{1}{2 \sigma^{2}}(\ln (y)-\mu)^{2}\right), y>0, \mu>0, \sigma>0,
$$

dengan $\mu$ adalah parameter lokasi (location) dan $\sigma$ adalah parameter skala (scale).

\subsection{Metode Bayes}

Misalkan data observasi $y=\left(y_{1}, y_{2}, \cdots, y_{n}\right)^{T}$ mempunyai distribusi tertentu dengan himpunan parameter $\beta=\left(\beta_{1}, \beta_{2}, \cdots, \beta_{k}\right)^{T}$ yang merupakan variabel random, maka distribusi posterior dari parameter $\beta$ atau $f(\beta \mid y)$ dapat dinyatakan dalam bentuk:

$$
f(\beta \mid y)=\frac{f(y \mid \beta) f(\beta)}{f(y)}
$$

dengan $f(y)=\int_{\Omega \beta_{1}} \cdots \int_{\Omega \beta_{k}} f(y \mid \beta) f(\beta) d \beta_{k} \cdots d \beta_{1}$ adalah normalizing constant, $f(\beta)$ adalah distribusi prior dari parameter $\beta$ yang berisi informasi yang diketahui tentang parameter $\beta$ sebelum pengamatan dilakukan. $f(y \mid \beta)=\prod_{i=1}^{n} f\left(y_{i} \mid \beta\right)$ adalah fungsi likelihood data yang berisi informasi sampel.

\subsection{Metode $\mathrm{HB}$ dalam $\mathrm{SAE}$}

Model HB yang digunakan pada penelitian ini adalah model lognormal dengan variabel prediktor berbasis area. Model tersebut didefinisikan sebagai [3]:

(i) Sampling model $y_{i} \mid \theta-\log \operatorname{normal}\left(\theta, \sigma_{[y]}^{2}\right), \sigma_{[y]}^{2}$ adalah ragam dari distribusi lognormal.

(ii) Linking model $\theta=x \beta+v$, dimana $v-N\left(0, \sigma_{[v]}^{2}\right.$ dan $\sigma_{[v]}^{2}=\frac{1}{\tau_{[v]}}$.

(iii) $\beta$ dan $\sigma_{[v]}^{2}$ saling independen dengan $\tau_{[v]} \sim \operatorname{unif}(0,100)$ dan $\beta-$ $N\left(\mu_{[\beta]}, \sigma_{[\beta]}^{2}\right)$. 


\section{Data dan Hasil}

Sumber data yang digunakan dalam penulisan ini menggunakan mikro data Sakernas 2016, data Podes 2014 dan data pada publikasi Kabupaten Padang Pariaman dalam angka 2016 yang dihasilkan oleh Badan Pusat Statistik. Variabel respon dalam penelitian ini adalah tingkat pengangguran di Kabupaten Padang Pariaman Provinsi Sumatera Barat yang dihitung berdasarkan data Sakernas 2016 melalui metode estimasi langsung. Variabel prediktor yang digunakan adalah Rasio SLTA/Sederajat $\left(X_{1}\right)$, Persentase keluarga pertanian $\left(X_{2}\right)$, Rasio industri mikro kecil (IMK) $\left(X_{3}\right)$, Persentase buruh tani dalam setiap anggota keluarga $\left(X_{4}\right)$ dan Kepadatan penduduk $\left(X_{5}\right)$.

\subsection{Estimasi Small Area Estimation Menggunakan Pendekatan HB Lognormal}

Jika Y adalah variabel random yang berdistribusi lognormal atau $y_{i}-L N\left(\theta, \sigma_{[y]}^{2}\right)$ dimana $\theta=x \beta+v, \sigma_{[y]}^{2}=\frac{1}{\tau_{[y]}}$ dengan $\theta-N\left(x \beta, \sigma_{[v]}^{2}\right), v-N\left(0, \sigma_{[v]}^{2}\right)$ dan $\sigma_{[v]}^{2}=\frac{1}{\tau_{[v]}}$ maka model Small Area Estimation dengan pendekatan HB menggunakan data tersebut juga berdasarkan distribusi lognormal, dengan prior pada model ini yaitu $\beta_{j}, \tau_{[v]}$, dan $\tau_{[y]}$. Fungsi likelihoodnya sebagai berikut :

$$
\begin{aligned}
f\left(y \mid \beta, \tau_{[v]}, \tau_{[y]}\right) & =\prod_{i=1}^{n} f\left(y_{i} \mid \beta, \tau_{[v]}, \tau_{[y]}\right), \\
& =\prod_{i=1}^{n}\left(\left(\frac{\tau_{[y]}^{1 / 2}}{y_{i}(2 \pi)^{1 / 2}} \exp \left[-\frac{\tau_{[y]}}{2}\left(\ln \left(y_{i}\right)-\theta\right)^{2}\right]\right) \times \frac{\tau_{[v]}^{1 / 2}}{2 \pi^{1 / 2}} \exp \left[-\frac{\tau_{[v]}}{2}\left(\theta_{i}-x_{i j} \beta_{j}\right)^{2}\right]\right) \\
& =\frac{\tau_{[y]}^{1 / 2} 2 \pi^{n / 2}}{\prod_{i=1}^{n} y_{i}} \exp \left[-\frac{\tau_{[y]}}{2} \sum_{i=1}^{n}\left(\ln \left(y_{i}\right)-\theta\right)^{2}\right] \times \frac{\tau_{[v]}^{n / 2}}{2 \pi^{n / 2}} \exp \left(-\frac{\tau_{[v]}}{2} \sum_{i=1}^{n}\left(\theta_{i}-\sum_{j=1}^{k} x_{i j} \beta_{j}\right)^{2}\right) .
\end{aligned}
$$

Tipe distribusi prior yang digunakan adalah conjugate, dengan distribusi prior $\beta_{j}-N\left(\mu_{[\beta]_{j}}, \sigma_{[\beta]_{j}}^{2}\right)$ dan $\tau_{[y]} \sim \operatorname{Gamma}\left(a_{\left(\tau_{[y]}\right)}, b_{\left(\tau_{[y]}\right)}\right)$ dan $\tau_{[v]} \sim$ unif $(0,100)$. Kombinasi antar fungsi likelihood dan distribusi prior gabungan akan membentuk distribusi posterior gabungan dari seluruh parameter yang akan di estimasi. Bentuk proposional distribusi posterior sebagai berikut.

$$
\begin{aligned}
& f\left(\beta, \tau_{[v]}, \tau_{[y]} \mid y\right) \propto \frac{\tau_{[y]}^{n / 2}}{\prod_{i=1}^{n} y_{i}} \exp \left(-\frac{\tau_{[y]}}{2} \sum_{i=1}^{n}\left(\ln \left(y_{i}\right)-\theta\right)^{2}\right) \\
& \times \tau_{[y]}^{n / 2} \exp \left(-\frac{\tau_{[v]}}{2} \sum_{i=1}^{n}\left(\theta_{i}-\sum_{j=1}^{k} x_{i j} \beta_{j}\right)^{2}\right) \\
& \times \tau_{[\beta]_{j}}^{1 / 2} \exp \left(-\frac{\tau_{[\beta]_{j}}}{2}\left(\beta_{j}-\mu_{[\beta]_{j}}\right)^{2}\right) \\
& \times \tau_{[y]}^{a_{\left(\tau_{[y]}\right)}}-1 \\
& \exp \left(-b_{\left(\tau_{[y]}\right)} \times \tau_{[y]}\right)
\end{aligned}
$$


Proses penyelesaian distribusi posterior marginal setiap parameter diatas mengandung integral dengan dimensi yang cukup tinggi dan kompleks sehingga untuk menyelesaikannya digunakan pendekatan numerik melalui MCMC dan Gibbs Sampling. Proses tersebut dilakukan melalui pengambilan sampel secara berulang melalui bentuk full conditional posterior. bentuk distribusi full conditional posterior setiap parameter yang akan diestimasi adalah sebagai berikut.

(a) Distribusi full conditional posterior untuk parameter $\beta_{j} f\left(\beta_{j} \mid y, \beta_{\backslash j}, \tau_{[v]}, \tau_{[y]}\right) \propto$

$$
\left.\left(\tau_{[v]}^{n} \cdot \tau_{[\beta]_{j}}\right)^{1 / 2} \exp \left(\frac{1}{2}\left(\tau_{[v]} \sum_{i=1}^{n}\left(\theta_{i}-\sum_{j=1}^{k} x_{i j} \beta_{j}\right)^{2}\right)+\tau_{[\beta]_{j}}\left(\beta_{j}-\mu_{[\beta]_{j}}\right)^{2}\right)\right) .
$$

(b) Distribusi full conditional posterior untuk $\tau_{[y]} \quad f\left(\tau_{[y]} \mid y, \beta, \tau_{[v]}\right) \propto$

$$
\tau_{[y]}^{a_{\tau_{[y]}}+\frac{n}{2}-1} \exp \left(\ln \frac{1}{-} \prod_{i=1}^{n} y_{i}+\left(\tau_{[y]}\left(-\frac{1}{2} \sum_{i=1}^{n}\left(\ln \left(y_{i}\right)-\theta\right)^{2}-b_{\tau_{[y]}}\right)\right) .\right.
$$

(c) Distribusi full conditional posterior untuk $\tau_{[v]} f\left(\tau_{[v]} \mid y, \beta, \tau_{[y]}\right) \sim \operatorname{gamma}\left(\frac{n}{2}+\right.$

$$
\left.1,\left(-\frac{1}{2} \sum_{i=1}^{n}\left(\theta_{i}-\sum_{j=1}^{k} x_{i j} \beta_{j}\right)^{2}\right)\right) \text {. }
$$

Proses estimasi model Small Area Estimation dengan pendekatan Hierarchical Bayesian (HB) Lognormal dilakukan menggunakan MCMC dan algoritma Gibbs Sampling dengan iterasi sebanyak 10.000 kali dan thin 3.000. Berdasarkan sampel sebanyak 10.000 tersebut, hasil estimasi yang diperoleh telah memenuhi sifat MCMC yang dapat dilihat dari MCMC diagnostic plot pada Gambar 1, 2, 3 dan 4.

(1) Trace plot untuk estimasi $\beta_{0}$ pada gambar 1 menunjukkan nilai random dengan pola yang stasioner. Selain itu, serial nilai sampel yang dihasilkan juga menunjukkan pola random yang stabil dalam suatu domain tetap. Serial plot untuk estimasi $\beta_{0}$ ditunjukkan pada Gambar 2 .

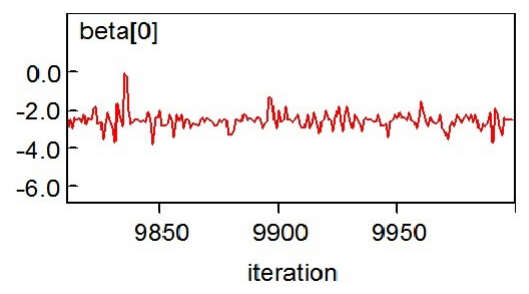

Gambar 1. plot trace untuk 10.000 iterasi pada parameter $\beta_{0}$

(2) Autocorrelation plot untuk estimasi $\beta_{0}$ dan $\beta_{1}$ pada Gambar 3 memperlihatkan hanya nilai autokorelasi pertama sampel yang tinggi, ini menunjukkan bahwa sampel baik dilakukan dan nilai autokorelasi selanjutnya mendekati nol, ini menunjukkan bahwa iterasi satu dengan yang lainnya saling bebas. Ini berarti bahwa sampel yang dibangkitkan dalam proses MCMC memiliki sifat yang random. 
Pendugaan Angka Pengangguran dengan Hierarchical Bayes (HB) Lognormal 19 19

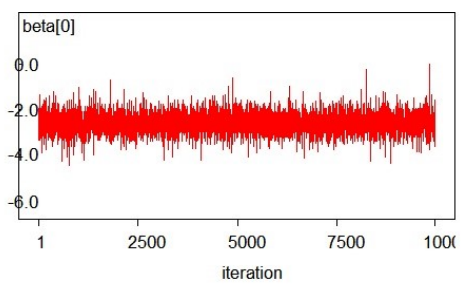

Gambar 2. Serial plot untuk 10.000 iterasi pada parameter $\beta_{0}$

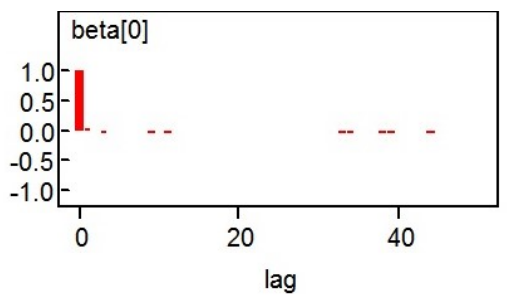

Gambar 3. Autocorrelation plot untuk 10.000 iterasi pada parameter $\beta_{0}$

(3) Quantiles plot pada Gambar 4 menujukkan ergodic mean, hasil estimasi parameter yang dihasilkan telah mencapai nilai yang stabil dan berada dalam credible interval

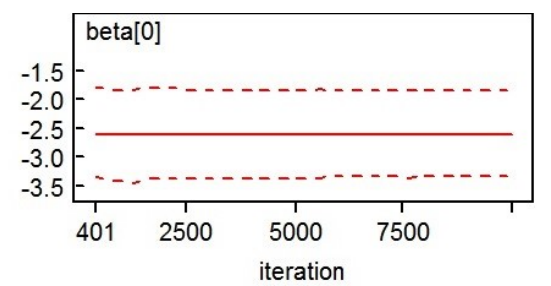

Gambar 4. Quantiles plot untuk 10.000 iterasi pada parameter $\beta_{0}$

Dari distribusi posterior diatas, dapat dicari distribusi posterior marginal dari masing-masing parameter dengan melakukan perhitungan menggunakan metode MCMC dan Gibbs Sampling melalui bentuk full conditional posterior. Banyaknya Update yang dijalankan adalah 10.000 dengan thin 3000.

Pendugaan dilakukan dengan bantuan Winbugs. Parameter hasil pendugaan disajikan pada Tabel 1.

Hasil estimasi parameter $\beta$ model Small Area Estimation dengan pendekatan Hierarchical Bayesian (HB) Lognormal untuk data Tingkat Pengangguran Terbuka (TPT) dapat dilihat pada Tabel 1 . Tabel tersebut memperlihatkan bahwa dengan nilai $\beta_{0}=-2,600000$ dan $\beta_{1}=0,007224$ secara statistik mempunyai pengaruh yang 
Tabel 1. Nilai Estimasi Parameter Model Small Area Estimation dan Credible Intervalnya untuk Data TPT Kabupaten Padang Pariaman 2015 menggunakan Pendekatan Hierarchical Bayesian (HB) Lognormal

\begin{tabular}{|c|l|l|l|l|}
\hline Parameter & $\begin{array}{l}\text { Nilai } \\
\text { Estimasi }\end{array}$ & $\begin{array}{l}\text { Standar } \\
\text { Deviasi }\end{array}$ & MC error & Credible Interval \\
\hline$\beta_{0}$ & $-2,600000$ & 0,376700 & 0,004230 & $-3,349000 \leq \beta_{0} \leq-1,848000$ \\
\hline$\beta_{1}$ & 0,007224 & 0,003279 & 0,000031 & $0,000693 \leq \beta_{1} \leq 0,013750$ \\
\hline$\beta_{2}$ & $-0,001022$ & 0,004917 & 0,000054 & $-0,010930 \leq \beta_{2} \leq 0,008735$ \\
\hline$\beta_{3}$ & $-0,000025$ & 0,001272 & 0,000015 & $-0,002573 \leq \beta_{3} \leq 0,002516$ \\
\hline$\beta_{4}$ & 0,001599 & 0,006006 & 0,000069 & $-0,010530 \leq \beta_{4} \leq 0,013710$ \\
\hline$\beta_{5}$ & $-0,000537$ & 0,000410 & 0,000004 & $-0,001352 \leq \beta_{5} \leq 0,000302$ \\
\hline$\tau_{[v]}$ & 0,0588 & 0,0404 & 0,000453 & $0,0110500 \leq \tau_{(v)} \leq 0,164700$ \\
\hline$\tau_{[y]}$ & 0,005894 & 0,015140 & 0,000130 & $0,000000 \leq \tau_{(y)} \leq 0,050570$ \\
\hline
\end{tabular}

signifikan terhadap Tingkat Pengangguran Terbuka (TPT) di Kabupaten Padang Pariaman. Hal ini ditunjukkan dari nilai $\beta_{0}$ dan $\beta_{1}$ berada dalam credible interval yang tidak melewati titik nol.

Selanjutnya akan dilihat perbandingan hasil estimasi langsung dan hasil estimasi metode Hierarchical Bayesian (HB) Lognormal dengan melihat nilai standar error.

Tabel 2. Perbandingan antara Penduga Langsung dengan Penduga HierarchicalBayesian (HB) Lognormal

\begin{tabular}{|l|l|l|l|l|}
\hline \multirow{2}{*}{ Kecamatan } & \multicolumn{2}{l|}{ Penduga Langsung } & \multicolumn{2}{l}{ Penduga HB } \\
\cline { 2 - 5 } & $\hat{y}$ & $\begin{array}{l}\text { Standar } \\
\text { Error }\end{array}$ & $\hat{y}$ & $\begin{array}{l}\text { Standar } \\
\text { Error }\end{array}$ \\
\cline { 2 - 5 } & & 0,0027 & 0,0572 & 0,0007 \\
\hline VII Koto Sungai Sariak & 0,0562 & 0,0022 & 0,0460 & 0,0007 \\
\hline Batang Anai & 0,0442 & 0,0008 & 0,0649 & 0,0004 \\
\hline Lubuk Alung & 0,0659 & 0,0056 & 0,0746 & 0,0012 \\
\hline Sintuk Toboh Gadang & 0,0753 & 0,0043 & 0,0408 & 0,0007 \\
\hline Ulakan Tapakis & 0,0403 & 0,0047 & 0,0576 & 0,0007 \\
\hline Nan Sabaris & 0,0566 & 0,0027 & 0,0724 & 0,0012 \\
\hline 2 X 11 Enam Lingkung & 0,0732 & 0,0071 & 0,0697 & 0,0006 \\
\hline Enam Lingkung & 0,0686 & 0,0016 & 0,0580 & 0,0010 \\
\hline 2 X 11 Kayu Tanam & 0,0567 & 0,0057 & 0,0999 & 0,0012 \\
\hline Patamuan & 0,1009 & 0,0047 & 0,1226 & 0,0100 \\
\hline Padang Sago & 0,1206 & 0,2302 & 0,0677 & 0,0007 \\
\hline V Koto Kp Dalam & 0,0684 & 0,0032 & 0,007 \\
\hline V Koto Timur & 0,1122 & 0,0032 & 0,1107 & 0,0011 \\
\hline Sungai Limau & 0,0632 & 0,0034 & 0,0633 & 0,0008 \\
\hline Batang Gasan & 0,091 & 0,0085 & 0,0927 & 0,0019 \\
\hline Sungai Geringging & 0,0705 & 0,0021 & 0,0713 & 0,0007 \\
\hline IV Koto Aur Malintang & 0,09 & 0,0024 & 0,0891 & 0,0008 \\
\hline
\end{tabular}

Berdasarkan Tabel 2, hasil estimasi Tingkat Pengangguran Terbuka (TPT) menggunakan model Small Area Estimation Pendekatan Hierarchical Bayesian (HB) Lognormal mempunyai nilai standar error yang lebih kecil dibandingkan dengan estimasi TPT dengan pendugaan langsung. Sehingga dapat dikatakan 
Pendugaan Angka Pengangguran dengan Hierarchical Bayes (HB) Lognormal 21

bahwa metode Small Area Estimation Pendekatan Hierarchical Bayesian (HB) Lognormal lebih baik daripada dengan pendugaan langsung.

\section{Kesimpulan}

Berdasarkan hasil penelitian diperoleh Hasil estimasi Tingkat Pengangguran Terbuka (TPT) menggunakan model Small Area Estimation Pendekatan Hierarchical Bayesian (HB) Lognormal mempunyai nilai standar error yang lebih kecil dibandingkan dengan estimasi TPT dengan pendugaan langsung. Sehingga dapat dikatakan bahwa model Small Area Estimation Pendekatan Hierarchical Bayesian (HB) Lognormal lebih baik daripada dengan pendugaan langsung.

\section{Daftar Pustaka}

[1] Johnson, N.L., Kotz, S., dan Balakrishnan, N. 1995. Continues Univariate Distributions. Volume $12^{\text {nd }}$ edition. John Wiley and Sons, New York.

[2] Raudenbush, S.W. dan A.S. Bryk. 2002. Hierarchical Linear Models: Applications and Data Analysis Methods. $2^{\text {nd }}$ edition, Sage Publications, Thousand Oaks.

[3] Rao, J.N.K. 2003. Small Area Estimation. John Wiley and Sons, New York. 